\title{
Propriedades do pólen e do estigma de Ocimum basilicum L. (cultivar Maria Bonita) para aumentar a eficiência de cruzamentos em programas de melhoramento
}

\author{
BRITO, A.C. ${ }^{*}$; SOUZA, J.D. ${ }^{1}$; REBOUÇAS, T.N.H. ${ }^{1}$; AMARAL, C.L.F. ${ }^{2}$ \\ ${ }^{1}$ Universidade Estadual do Sudoeste da Bahia, Estrada do Bem-Querer, km 04 Bairro Universitário, CEP: 45083- \\ 900, Vitória da Conquista-Brasil *ana.carla@ufv.br² Universidade Estadual do Sudoeste da Bahia, Rua José \\ Moreira Sobrinho, Jequiezinho, CEP: 45206-190, Jequié-Brasil
}

\begin{abstract}
RESUMO: Ocimum basilicum, cv. Maria Bonita (Lamiaceae), conhecido como manjericão, é espécie que apresenta propriedades aromáticas, condimentares e medicinais, por ser rico em óleos essenciais. É muito usado nas indústrias farmacêuticas e de alimentos em geral. O objetivo deste trabalho foi estudar as propriedades do pólen e estigma do manjericão (cultivar Maria Bonita) identificando procedimentos simples que possam contribuir para programas de melhoramento. Para análise da disponibilidade, viabilidade do pólen e receptividade de estigma, botões florais foram coletados de hora em hora ao longo do dia, e lâminas eram montadas e coradas, para observação em microscópio óptico. Foi verificado que o manjericão apresenta antese diurna, assincrônica e com a maioria das flores se abrindo entre 10:00 e 11:00 horas. Quanto ao estudo do pólen foi verificado que a viabilidade manteve-se elevada ao longo do dia e a conservação por até 90 dias demonstrou bons níveis de viabilidade. $O$ estigma apresentou receptividade desde a pré-antese até a pós-antese. Estas informações são relevantes para os melhoristas que desejam fazer seleção de genótipos ou hibridações em programas de melhoramento, contribuindo para aumentar o potencial da espécie que já se destaca como produtora de óleos essenciais.
\end{abstract}

Palavras-chave: Ocimum basilicum, viabilidade de pólen, receptividade de estigma, conservação

\begin{abstract}
Ocimum basilicum L. (cultivar Maria Bonita) pollen and stigma properties to improve the efficiency of crossings in plant breeding programs. Known as basil, Ocimum basilicum cv. Maria Bonita (Lamiaceae) is a species that presents aromatic, condimental and medicinal properties, since it is rich in essential oils. This species is largely used in pharmaceutical and food industries. The aim of this work was to study basil (cultivar Maria Bonita) pollen and stigma properties, identifying simple procedures that can contribute to plant breeding programs. To analyze pollen availability and viability, besides stigma receptivity, flower buds were collected at every hour throughout the day, and slides were mounted, stained and observed under an optical microscope. Basil presented diurnal asynchronous anthesis and most flowers opened between 10:00 and 11:00 a.m. As regards pollen analysis, viability was high throughout the day and its conservation until 90 days was good. Stigma presented receptivity from pre- to post-anthesis. These data are relevant to breeders who wish to select genotypes or hybridizations in plant breeding programs, contributing to improve the potential of this species, which already represents a producer of essential oils.
\end{abstract}

Key words: Ocimum basilicum, pollen viability, stigma receptivity, conservation

\section{INTRODUÇÃO}

O gênero Ocimum L. (Lamiaceae) compreende, aproximadamente, 50 espécies (Miele et al., 2001) que se distribuem amplamente no planeta, sobretudo nas regiões tropicais e subtropicais (Vieira \& Simon, 2000), Muitas espécies são usadas para fins medicinais, na culinária e no controle de pragas na agricultura, pois são ricas em óleos essenciais (Grayer et al., 1996). "Maria Bonita" é o primeiro cultivar de manjericão registrado no Registro Nacional de Cultivares (RNC) pelo

Recebido para publicação em 09/04/09

Aceito para publicação em 03/10/09

Rev. Bras. PI. Med., Botucatu, v.12, n.2, p.208-214, 2010. 
Ministério da Agricultura, Pecuária e Abastecimento no Brasil, e foi obtida a partir do programa de melhoramento genético da Universidade Federal de Sergipe (Blank et al., 2007).

No Brasil, é cultivada, principalmente, por pequenos produtores rurais da região Nordeste para a comercialização da planta como condimento (Blank et al., 2004; Albuquerque \& Andrade, 1998). O incremento na produção do manjericão apresenta relevância social, uma vez que as propriedades estimulantes, anti-gripal, diurética e anti-espasmódica, etc., dos chás e preparados das folhas e inflorescências são amplamente difundidas nas comunidades de baixa renda do semi-árido nordestino, sendo uma alternativa aos medicamentos alopáticos no tratamento de diversas enfermidades. Transferir tecnologia de propagação desta planta medicinal a pequenos e médios produtores interessados em cultivá-la, torna-se uma alternativa de geração de renda, para a comercialização da matéria prima para as indústrias, que utilizam o óleo essencial.

De acordo com Anderson (1995), o conhecimento de aspectos da biologia floral das espécies permite compreender melhor a história evolutiva e os mecanismos envolvidos, e pode ser importante ferramenta no estabelecimento de programas de conservação da espécie.

Segundo Sousa et al. (2005), o pólen é o material básico utilizado nas técnicas de hibridação. A avaliação do desenvolvimento biológico de grãos de pólen é fundamental para os trabalhos de biologia reprodutiva e melhoramento genético, pois permite obter maior sucesso nos cruzamentos, realizados com a finalidade de obter novos híbridos e/ou aumentar a variabilidade (Nunes et al., 2001).

Para assegurar o sucesso nas hibridações controladas é importante que o pólen a ser utilizado tenha boa viabilidade. Em geral, o pólen colhido de flores em adequado estádio de desenvolvimento e corretamente preparado não necessita de testes de viabilidade. Entretanto, não são raras as situações em que o pólen a ser usado tenha sido colhido em outra região, ou mesmo, fornecido via intercâmbio com outros países. Por outro lado, devido a nãocoincidência de floração, é preciso, muitas vezes, armazenar o pólen colhido em um ano, para ser utilizado no ano seguinte. Neste caso é recomendável testar a viabilidade do mesmo antes da utilização (Einhardt et al., 2006).

A receptividade dos estigmas também é fator fundamental para se determinar o melhor período de deposição do pólen na flor. O estigma normalmente, dependendo da espécie de planta, produz substâncias viscosas que promovem a aderência do pólen, essa característica contribui para provável fertilização, com formação de frutos e sementes (Almeida, 2007).
É notória a necessidade da indústria nacional e de instituições de fomento investir em pesquisa e desenvolvimento para que sejam alcançados os padrões de qualidade exigidos pelo mercado. Apesar de constantes estudos, ainda são poucas as informações da biologia floral de algumas espécies, principalmente do manjericão (cv Maria Bonita), sendo relevante aprimorar os conhecimentos sobre alguns aspectos da biologia floral.

Este trabalho teve como objetivo estudar as propriedades do pólen e do estigma do manjericão cultivar Maria Bonita com vistas a aumentar a eficiência de cruzamentos em programas de melhoramento, dada a grande relevância farmacológica e a condição aromática e condimentar desta espécie.

\section{MATERIAL E MÉTODO}

\section{Local do estudo}

Os estudos foram conduzidos, em área experimental da Universidade Estadual do Sudoeste da Bahia-UESB, localizada no Campus de Vitória da Conquista - BA (1451' S e 4050' W, altitude média de $928 \mathrm{~m}$ ), bem como, nos Laboratórios de Biotecnologia, e da Biofábrica da mesma Instituição de Ensino Superior.

\section{Material vegetal}

As plantas utilizadas no experimento foram oriundas de mudas cultivadas em casa de vegetação e transplantadas com aproximadamente 45 dias para vasos com capacidade de 6 litros de substrato, contendo solo e húmus de minhoca (3:1).

\section{Eventos florais}

Para determinação da antese, foram feitas observações diárias da abertura de 50 botões florais de 10 indivíduos escolhidas aleatoriamente e, previamente, marcadas no período de 7:00 até às 18:00 horas durante 15 dias.

\section{Disponibilidade dos grãos de pólen}

Foi obtida por meio da contagem dos grãos de pólen, advindos de uma antera de uma flor colhida aleatoriamente. Esta antera foi macerada sobre uma lâmina e os grãos corados com carmim acético 1\% e levada para observação e contagem em microscópio óptico, sendo 3 lâminas montadas por hora, a partir da antese, até as 18:00 horas. Este experimento foi conduzido nos dias 27, 28 e 29 de maio de 2008.

\section{Viabilidade dos Grãos de Pólen}

A viabilidade dos grãos de pólen foi analisada a partir de lâminas coradas com carmim acético, segundo a técnica de Linsley \& Cazier (1963), em 
diferentes estádios de desenvolvimento floral, compreendidos nos horários de 7:00 às 18:00 horas em intervalos de uma hora, nos dias 27,28 e 29 de maio de 2008.

Foram observados sob microscópio óptico 100 grãos de pólen/lâmina e 3 lâminas a cada hora. Os grãos de pólen foram classificados como normais/ viáveis, quando apresentaram coloração avermelhada ou anormais/inviáveis, quando apresentaram coloração amarronzada. A viabilidade nos diferentes estádios de desenvolvimento floral foi demonstrada por análise de regressão.

\section{Conservabilidade dos grãos de pólen}

Foram utilizados 60 tubos eppenddorf contendo 2 anteras por tubo. Cada tubo foi preparado previamente com uma camada de sílica gel, para reter a umidade, e coberto com um pouco de algodão para sustentar as anteras. Dos tubos, 30 deles ficaram em geladeira à temperatura de $10^{\circ} \mathrm{C} \pm 1^{\circ} \mathrm{C}$ e os outros 30 no congelador com temperatura média de $-10^{\circ} \mathrm{C} \pm$ $1^{\circ} \mathrm{C}$. De 30 em 30 dias, durante 3 meses, foram montadas 10 lâminas com macerados das anteras contendo os grãos de pólen, que foram corados com carmim acético a $1 \%$ e observados sob microscópio óptico. O delineamento experimental foi inteiramente casualizado, em esquema fatorial de $3 \times 2$ (tempo de armazenamento $x$ temperatura) com 10 repetições. Os dados foram analisados pelo SISVAR 4.0 (Ferreira, 2000).

\section{Receptividade dos estigmas}

A receptividade foi verificada pelo aspecto viscoso e umectante (Almeida, 1986) e testada utilizando peróxido de hidrogênio $\left(\mathrm{H}_{2} \mathrm{O}_{2}\right)$ a $3 \%$ (Kearns \& Inouye, 1993). As flores foram coletadas em diferentes estádios de desenvolvimento floral, três estigmas por hora, no período de 7:00 às 18:00 horas, nos dias 27, 28 e 29 de maio de 2008. Sobre os estigmas foi gotejado o peróxido de hidrogênio a 3\% e os que apresentaram formação de bolhas foram considerados receptivos. As variações da receptividade nos diferentes estádios de desenvolvimento floral, ao longo do dia, foram demonstradas por análise de regressão.

\section{RESULTADO E DISCUSSÃO}

\section{Eventos florais}

O desenvolvimento floral foi avaliado nos estádios de pré-antese, quando os botões apresentavam-se fechados e intumescidos; antese, na qual os botões florais abrem-se assincronicamente deixando totalmente expostos o estigma e os estames, e pós-antese, quando ocorre a total distensão das pétalas e sépalas. Todos os botões
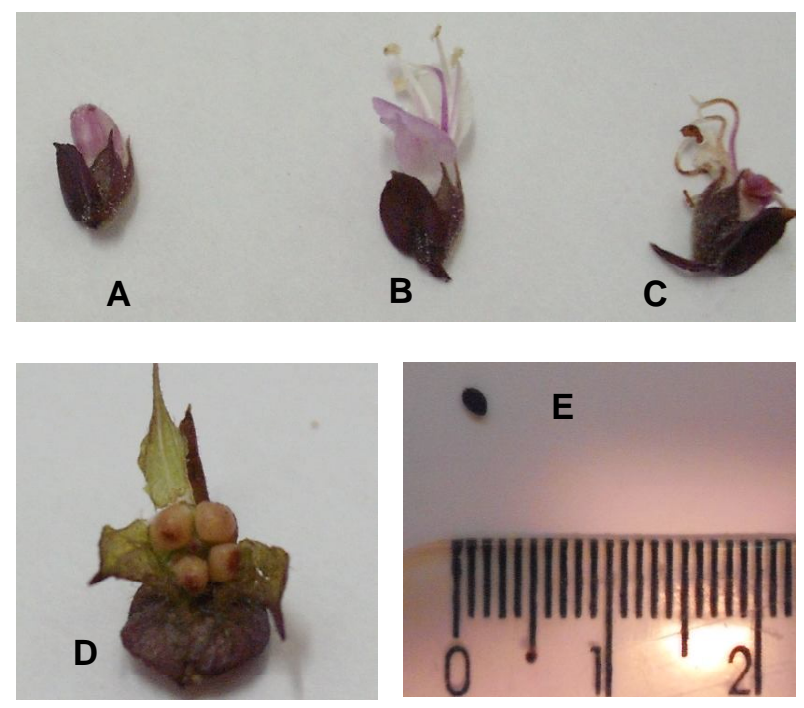

FIGURA 1. Fases de desenvolvimento da flor encontradas em uma mesma inflorescência: (A) botão; (B) flor aberta; (C) flor em senescência; (D) frutos; $(E)$ semente.

florais não se abrem simultaneamente em mesma inflorescência, sendo possível encontrar flores em diferentes estádios de desenvolvimento na mesma planta, durante um dia (Figura 1).

Na pré-antese, embora a flor permaneça fechada, ocorre liberação de grãos de pólen sobre o estigma, que já se encontra visualmente viscoso.

A antese ocorre com maior freqüência entre 10:00 e 11:00 horas, com anteras já deiscentes e grãos de pólen disponíveis, os quais podem ser conduzidos por eventuais polinizadores que iniciam e intensificam as atividades neste período, principalmente de abelhas que buscam o néctar e pólen como recursos alimentares. Ocorre emissão agradável de odor neste período, o que favorece a frequência das visitas.

$\mathrm{Na}$ pós-antese ocorre, provavelmente, a fertilização com consequente crescimento do tubo polínico e posterior formação de frutos e sementes. A longevidade floral (período entre a antese e a senescência da corola) na cv. Maria Bonita foi de aproximadamente 24 horas.

\section{Disponibilidade dos grãos de pólen}

A disponibilidade dos grãos de pólen foi quantificada após a deiscência das anteras, o que ocorreu a partir da antese (10:00 horas). Nos dias avaliados houve declínio ao longo do dia, principalmente nas horas finais de avaliação (Figura 2), concordando com trabalho realizado por Almeida (2007) em O. sanctum L. As temperaturas nos dias de avaliação, com médias de $20^{\circ} \mathrm{C}$, podem ter provocado a queda na disponibilidade do pólen ao longo da análise.

A escassez do pólen no decorrer do dia pode 


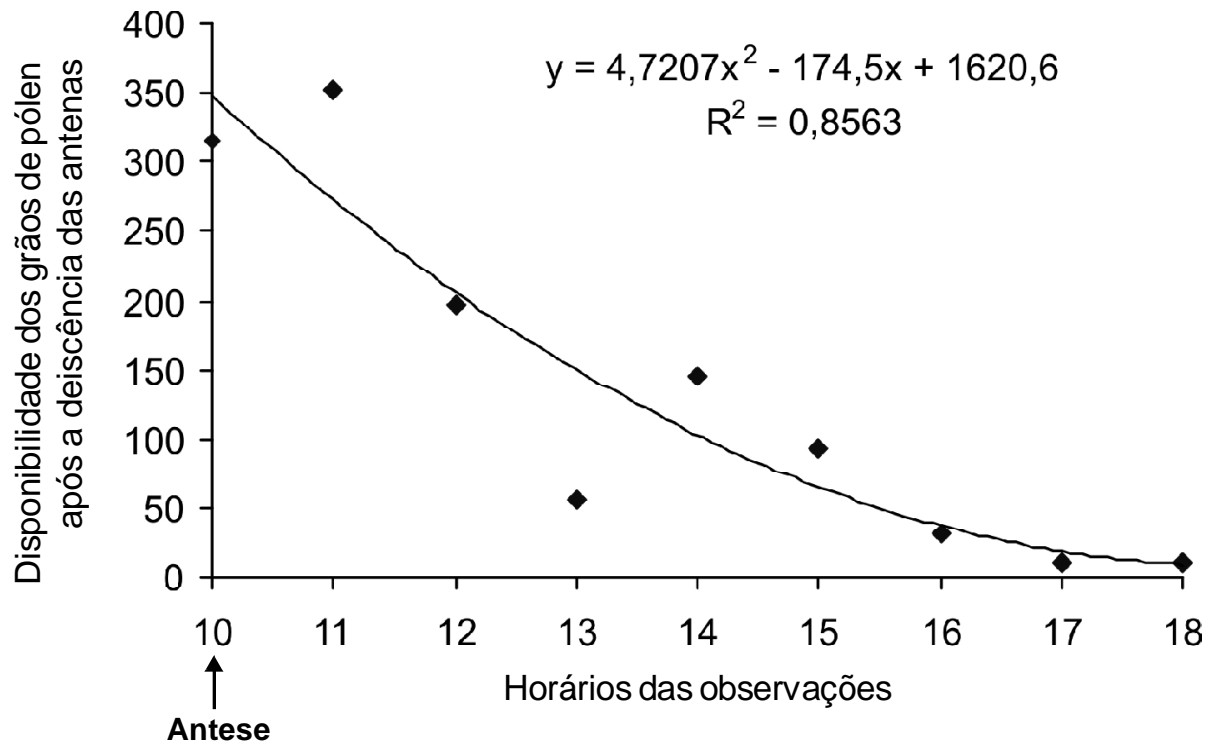

FIGURA 2. Estimativa do número de grãos de pólen disponíveis ao longo do dia, observados em 27,28 e 29 de maio de 2008. Vitória da Conquista - BA.

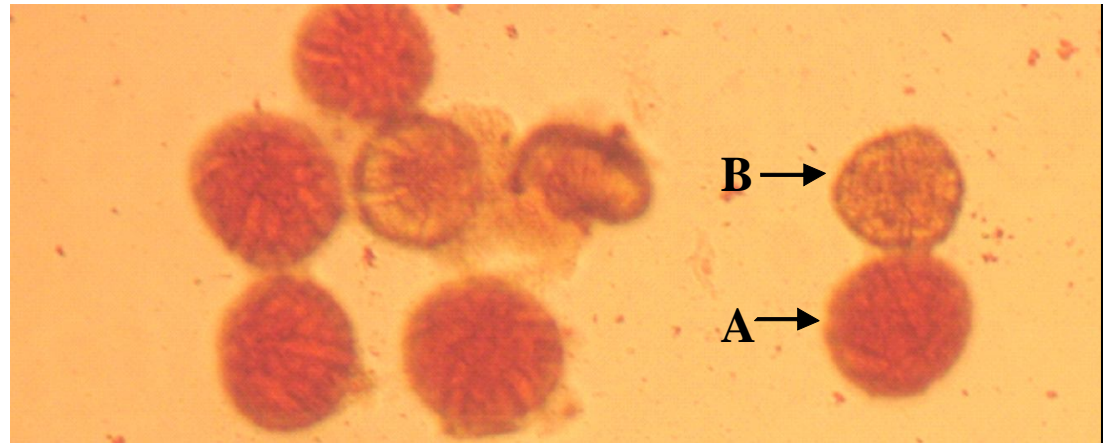

FIGURA 3. Grãos de pólen viáveis (A) e não-viáveis (B) após corados com carmim acético. Vitória da ConquistaBA, 2008.

ser provavelmente, considerada como um aspecto positivo, levando a supor, segundo Almeida (2007), a eficácia no transporte de pólen por algum agente polinizador, o que pode favorecer tanto a autopolinização quanto a fecundação cruzada. A presença de abelhas era comum ao longo de todo o dia e mais intensamente a partir das 10:00 horas. Harder \& Barret (1996) afirmam que a atividade dos visitantes florais afeta diretamente o fluxo de pólen permitindo a ocorrência tanto da autopolinização, quanto da fecundação cruzada, o que contribui no aumento da variabilidade genética.

\section{Viabilidade dos grãos de pólen}

O pólen viável apresentou-se avermelhado e os inviáveis de coloração marrom (Figura 3). Os grãos de pólen viáveis são facilmente percebidos devido à coloração exibida, com a utilização do corante carmim acético (Rigamoto \& Tyagi, 2002).

Durante os três dias de avaliação a viabilidade mostrou-se elevada ao longo do dia (Figura 4), com valores superiores a $80 \%$. Resultados semelhantes foram obtidos por Gonçalves et al. (2008) para Ocimum gratissimum L. e por Almeida et al. (2004) para Ocimum officinalis L. De acordo com Souza (2002) e Domingues et al. (1999) valores acima de $70 \%$ são considerados como de alta viabilidade, de 31 a $69 \%$ como média e até $30 \%$ baixa. A taxa de viabilidade do pólen ao longo de um dia pode variar devido, principalmente, à temperatura ambiente, como visto por Silva et al. (2000) em genótipos de tomateiro.

Para o Ocimum basilicum L., assim como para outras espécies, essa alta viabilidade dos grãos de pólen é característica altamente desejada pelos melhoristas para iniciarem programa de melhoramento genético, nas quais outras características são buscadas para aprimorar ou lançar novos cultivares promissores.

\section{Conservabilidade dos grãos de pólen}

Os grãos de pólen armazenados conservaram-se viáveis ao longo de toda a análise. Médias acima de $79 \%$ foram alcançadas tanto para 


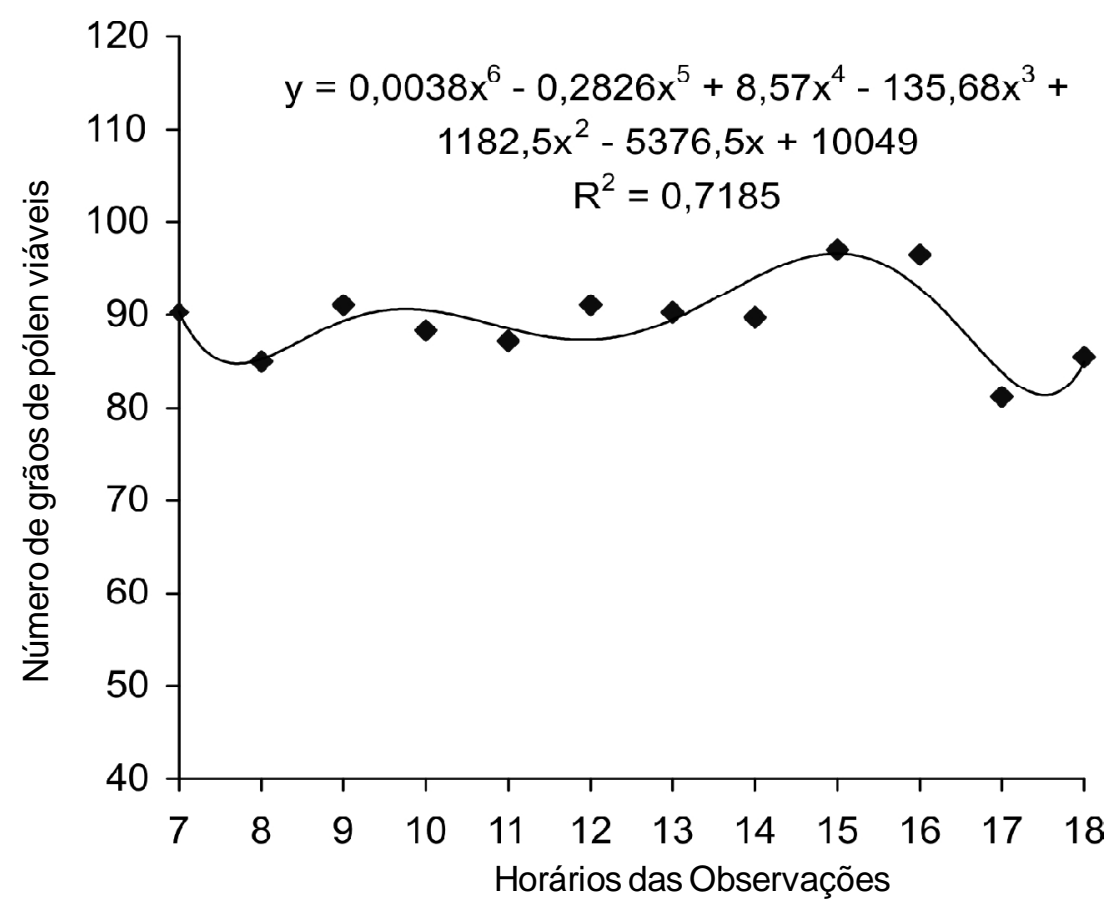

FIGURA 4. Estimativa do número de grãos de pólen viáveis ao longo de 12 h de avaliação, observados em 27, 28 e 29 de maio de 2008.

o pólen conservado em geladeira, quanto ao conservado em congelador (Tabela 1).

No ambiente geladeira o pólen avaliado aos 90 dias diminuiu pouco a viabilidade quando comparado às demais épocas de avaliação. Já no ambiente freezer as maiores médias foram alcançadas aos 60 dias (91,60\%), que entretanto não diferiram estatisticamente em relação às outras épocas de avaliação.

Com relação ao tempo de armazenamento, aos 90 dias o ambiente freezer proporcionou maior viabilidade do pólen. Com isso observou-se que, de acordo com o período de armazenamento, a menor temperatura utilizada elevou a chance de se obter altos níveis de viabilidade.

Esta é importante ferramenta em programas de melhoramento, pois nem sempre 0 pólen está disponível para o uso, quando necessita assim o armazenamento torna-se uma alternativa para que se tenha, sempre que necessário, pólen disponível e com alta viabilidade (Gomes et al., 2003; Souza et al., 2002).

\section{Receptividade dos estigmas}

A receptividade dos estigmas foi verificada durante todo o período avaliado. Flores com longos períodos de receptividade aumentam a probabilidade de ocorrência da polinização (Rathcke \& Lacey, 1985), e provável fertilização. Este dado é importante para o melhorista, pois permite a ele fazer os cruzamentos no período conveniente ao programa, já que o estigma apresenta longo período de
TABELA 1. Viabilidade de grãos de pólen armazenados e analisados aos 30,60 e 90 dias em diferentes ambientes. Vitória da Conquista-BA.

\begin{tabular}{cccc}
\hline Armazenamento & 30 dias & $\mathbf{6 0}$ dias & 90 dias \\
\hline Geladeira & $89,80 \mathrm{aA}$ & $88,30 \mathrm{aA}$ & $79,90 \mathrm{bB}$ \\
Freezer & $88,50 \mathrm{aA}$ & $91,60 \mathrm{aA}$ & $89,90 \mathrm{aA}$ \\
\hline Média & 88,00 & & \\
CV(\%) & 5,92 & & \\
\hline
\end{tabular}

Médias seguidas pela mesma letra na coluna não diferem estatisticamente pelo teste Tukey ao nível de $5 \%$ de probabilidade.

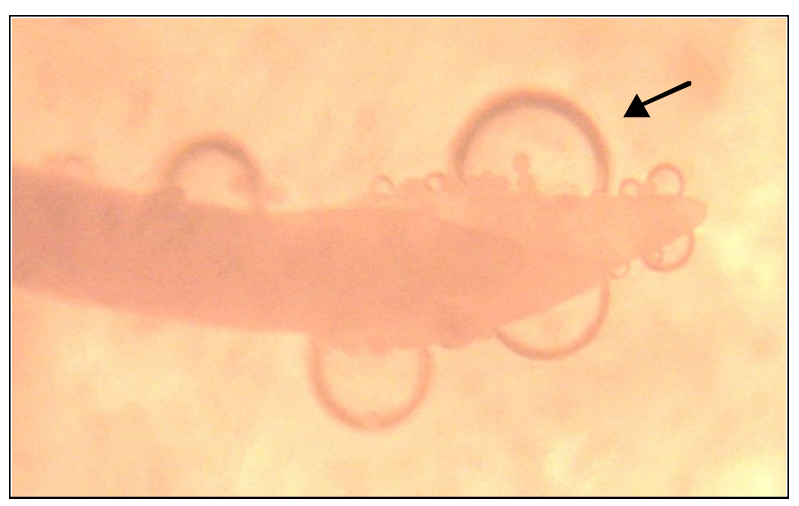

FIGURA5. Estigma receptivo evidenciando a formação de bolhas. 


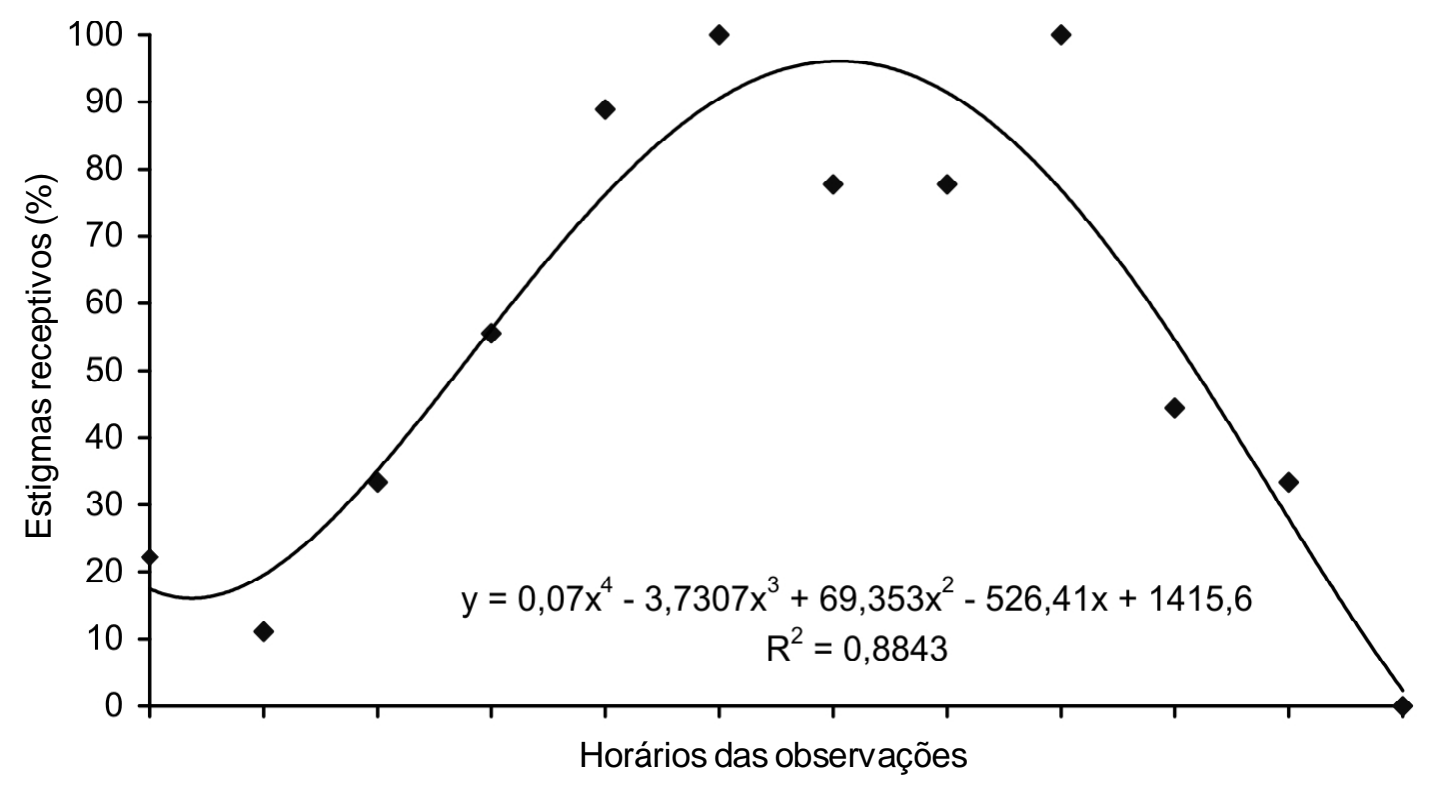

FIGURA 6. Estimativa de estigmas receptivos ao longo de 12 horas de avaliação, observados em 27, 28 e 29 de maio de 2008.

receptividade ao longo do dia.

Com o uso do peróxido de hidrogênio a 3\%, houve o borbulhamento na cavidade estigmática (Figura 5), indicando a atividade da peroxidase, tanto em flores em estádio de pré-antese, quanto em flores completamente abertas. A presença dessa enzima indica a receptividade do estigma (Kearns \& Inouye 1993).

Foi observado que, geralmente, em flores a partir da antese ocorreu maior número de estigmas receptivos (Figura 6). Resultado semelhante foi obtido por Manju \& Rawat (2006), quando observaram que os estigmas de flores de lima, variedade Kagzi, estavam mais receptivos na antese, ou seja, no momento da abertura das anteras e liberação dos grãos de pólen.

Para o sucesso da polinização, o pólen, transferido para o estigma receptivo, deve germinar, ocorrendo assim a fertilização. Em muitos casos, a fertilização também pode ocorrer quando o grão de pólen é depositado antes do período receptivo dos estigmas, desde que permaneça viável em tempo suficiente para poder germinar assim que a flor se torne receptiva (Ramos et al., 2002).

De acordo com o local e épocas das avaliações pode-se concluir que o cultivar Maria Bonita manteve a viabilidade polínica elevada ao longo do dia, assim como o pólen que foi armazenado tanto em geladeira, quanto em freezer. Os estigmas são receptivos desde a pré-antese, com maior frequência a partir da antese.

\section{AGRADECIMENTO}

À Fundação de Amparo à Pesquisa do
Estado da Bahia - FAPESB, pela concessão da bolsa de mestrado, e a Universidade Estadual do Sudoeste da Bahia - UESB.

\section{REFERÊNCIA}

ALBUQUERQUE, U.P.; ANDRADE, L.H.C. Etnobotánica del género Ocimum L. (Lamiaceae) en las comunidades afrobrasileñas. Anales del Jardim Botânico de Madrid, v.56, n.1, p.107-18, 1998.

ALMEIDA, E.C. Biologia floral e mecanismos de reprodução em Crotaria mucrota. Ceres, v.33, n.190, p.528-40, 1986.

ALMEIDA, O.S. Biologia floral. Tendências reprodutivas e efeito alelopático da tulase (Ocimum sanctum L.). 2007. 88p. Dissertação (Mestrado - Curso de Pós-graduação em Agronomia, área de concentração em Fitotecnia) Universidade Estadual do Sudoeste da Bahia, Vitória da Conquista.

ANDERSON, G.J. Systematics and reproductive biology. In: $\mathrm{HOCH}$, P.C.; STEPHENSON, A.G. Experimental and molecular approaches to plant biosystematics: monographs in systematics. St. Louis: Missouri Botanical Garden, 1995. p.263-72.

BLANK, A.F. et al. Maria Bonita: cultivar de manjericão tipo linalol. Pesquisa Agropecuária Brasileira, v.42, n.12, p.1811-3, 2007.

BLANK, A.F. et al. Caracterização morfológica e agronômica de acessos de manjericão e alfavaca. Horticultura Brasileira, v.22, p.113-6, 2004.

DOMINGUES, E.T.; TULMANN NETO, A.; TEÓFILO SOBRINHO, J. Viabilidade do pólen em cultivares de laranja doce. Scientia Agricola, v.56, n.2, p.265-72, 1999. EINHARDT, P.M.; CORREA, E.R.; RASEIRA, M.C.B. Comparação entre métodos para testar a viabilidade de pólen de pessegueiro. Revista Brasileira de Fruticultura, v.28, n.1, p.5-7, 2006. 
FERREIRA, D.F. Análises estatísticas por meio do Sisvar para Windows versão 4.0. In: REUNIÃO ANUAL DA REGIÃO BRASILEIRA DA SOCIEDADE INTERNACIONAL DE BIOMETRIA, 45., 2000, São Carlos. Anais... São Carlos: UFSCar, 2000, p.255-8.

GOMES, P.R. et al. Armazenamento do grão de pólen de cebola (Allium cepa L.). Revista Brasileira de Sementes, v.25, n.1, p.14-7, 2003.

GONÇALVES, C.B.S. et al. Atividade de insetos em flores de Ocimum gratissimum L. e suas interações com fatores ambientais. Revista Caatinga, v.21, n.3, p.128-33, 2008. GRAYER, R.J. et al. Infraespecific taxonomy and essencial oil chemotypes in sweet basil, Ocimum basilicum. Phytochemistry, v.43, n.5, p.1033-9, 1996.

HARDER, L.D.; BARRET, S.C.H. Pollen dispersal and mating patterns in animal-pollinated plants. In: LLOYD, D.G.; BARRET, S.C.H. (Eds.). Floral biology, studies on floral evolution in animal-pollinated plants. New York: Chapman \& Hall, 1996. p.140-90.

KEARNS, C.A.; INOUYE, D.W. Techinques for pollination biologists. Niwot: University Press of Colorado, 1993. 579p. LINSLEY, E.C.; CAZIER, M.A. Further observation on bees which take polen form plants of genus Solanum. Pan Pacific Entomologist, v.39, n.1, p.1-18, 1963.

MANJU, I.; RAWAT, S.S. Studies on floral biology of Kagzi lime (Citrus aurantifolia Swingle) under valley conditions of Garhwal Himalaya. Advances Plant Science, v.19, p.11-7, 2006.

MIELE, M. et al. Methyleugenol in Ocimum basilicum L. cv. Genovese Gigante. Jounal of Agricultural Food
Chemistry, v.49, p.517-21, 2001.

NUNES, J.C.O. et al. Germinação de pólen in vitro e receptividade do estigma em macieira cvs. Fuji e Golden Delicious. Revista Brasileira de Fruticultura, v.23, n.1, p.35-9, 2001.

RAMOS, J.D. et al. Produção de mudas de plantas frutíferas por semente. Informe Agropecuário, v.23, n.216, p.64-72, 2002.

RATHCKE, B.; LACEY, E.P. Phenological patterns of terrestrial plants. Annual Review of Ecology, Evolution, and Systematics, v.16, p.179-214, 1985.

RIGAMOTO, R.R.; TYAGI, A.P. Pollen fertility status in coastal plant species of rotuma Island. South Pacific Journal of Natural Science, v.20, p.30-3, 2002.

SOUSA, S.A. Cultura da Pinheira: caracterização de frutos, germinação e atributos de qualidade requeridos pelo sistema de comercialização. 2005. 70p. Dissertação (Mestrado - Curso de Pós-graduação em Ciências Agrárias) - Escola de Agronomia, Universidade Federal da Bahia, Cruz das Almas.

SOUZA, M.M.; PEREIRA, T.N.S.; MARTINS, E.R. Microsporogênese e microgametogênese associadas ao tamanho do botão floral e da antera e viabilidade polínica em maracujazeiro-amarelo (Passiflora edulis Sims f. flavicarpa degener). Ciência e Agrotecnologia, v.26, n.6, p.1209-17, 2002.

VIEIRA, R.F.; SIMON, J.E. Chemical characterisation of basil (Ocimum basilicum L.) found in markets and used in traditional medicine in Brazil. Economical Botany, v.54, p.207-16, 2000. 